\title{
Sociodemographic Predictors in Failure to Complete Outpatient Cardiac Rehabilitation
}

\author{
Behzad Heydarpour, MD¹, Mozhgan Saeidi, MSc ${ }^{1}$, \\ Parvin Ezzati, BS ${ }^{1}$, Ali Soroush, MD $^{2}$, Saeid Komasi, MSc $^{1}$
}

\begin{abstract}
${ }^{1}$ Cardiac Rehabilitation Center, Kermanshah University of Medical Sciences, Kermanshah; ${ }^{2}$ Lifestyle Modification Research Center, Imam Reza Hospital, Kermanshah University of Medical Sciences, Kermanshah, Iran
\end{abstract}

Objective To investigate the role of sociodemographic factors in failure to complete outpatient cardiac rehabilitation (CR).

Methods This was a retrospective study that used information obtained from the database of the cardiac rehabilitation department of a cardiac hospital in Iran. Data from 1,050 CR patients treated at the hospital between January 2001 and January 2013 was analyzed using binary logistic regression analysis.

Results Only $49 \%$ of the patients completed the CR program. After adjustment for baseline variables, it was found that the following were significantly associated with failure to complete the CR program: illiteracy $(\mathrm{p}<0.001)$, old age $(\mathrm{p}<0.001)$, being an employee or retired $(\mathrm{p}<0.05)$, having a low capacity for exercise $(\mathrm{p}<0.001)$, depression $(\mathrm{p}<0.001)$, low anxiety $(\mathrm{p}<0.001)$, and not currently being a smoker $(\mathrm{p}<0.001)$.

Conclusion Paying more attention to older patients with low literacy levels and limited exercise capacity, who are employed or retired, and who are not current smokers, and taking therapeutic measures to control psychological complications such as depression, may be effective in ensuring that patients complete outpatient cardiac rehabilitation.

Keywords Social characteristics, Demographic factors, Patient dropout, Outpatients, Rehabilitation, Cardiac disease

\section{INTRODUCTION}

Cardiovascular diseases are currently the main cause of mortality in the United States and other industrialized

Received February 27, 2015; Accepted June 19, 2015

Corresponding author: Saeid Komasi

Cardiac Rehabilitation Center, Imam Ali Hospital, Kermanshah University of Medical Sciences, Shahid Beheshti Boulevard, Kermanshah 67146, Iran Tel: +98-833-8380698, Fax: +98-833-8360043, E-mail: S_Komasi63@yahoo. com

(c) This is an open-access article distributed under the terms of the Creative Commons Attribution Non-Commercial License (http://creativecommons. org/licenses/by-nc/4.0) which permits unrestricted noncommercial use, distribution, and reproduction in any medium, provided the original work is properly cited.

Copyright $\odot 2015$ by Korean Academy of Rehabilitation Medicine countries; nearly one-third of adults die of these diseases [1]. Significant advances have been made in medical treatments for coronary artery disease and cardiac intensive care in recent decades [2]. However, the development and implementation of cardiac rehabilitation (CR) programs has lagged behind such advances. CR is one of the most important measures that can be taken after the occurrence of a cardiac event or cardiac surgery to lessen complications [3]. It is comprised of activities such as comprehensive medical assessment, exercise, risk factor modification, education, observation, and changes in patient behavior. CR is the process of learning how to manage chronic diseases or disabling conditions with the 
aim of restoring patients to their highest possible level of physical, mental, social, and occupational functioning [4].

CR is accomplished in 4 phases. The first phase begins before the patient is discharged from the hospital and includes assessment of the patient's physical, psychological and social needs; it is important that possible barriers to participating in CR are recognized. Patients are given expert recommendations regarding safe levels of physical and sexual activity, proper diet and drug use, and ways to quit smoking. In the second phase, which takes place shortly after discharge, patients are visited in their homes and called on the phone. Phase 3 , which lasts for 6 to 12 weeks, consists of at least two sessions of exercise per week. Physical activity is a key component of phase 3. Also, patients are given psychosocial consultation sessions to emphasize the importance of lifestyle changes. In phase 4 , which is the long-term consolidation of reformed behaviors, patients are monitored for the continuation of lifestyle changes [5].

CR programs are undertaken in order to improve patients' psychological and social states, to limit the physical and psychological effects of cardiovascular diseases, to minimize sudden death or repeated heart attack, and to control symptoms arising from coronary artery disease [6]. One study reported that the mortality rate of patients who participated in CR programs decreased by $25 \%$ [7]. Despite the advantages and effectiveness of the CR program, the results of prior investigations show that the participation rate in CR programs is low and the dropout rate is high [7-9]. Iran is not an exception to this rule; the results of one study [10] show that only $15 \%$ of cardiac patients participate in CR programs and $68.7 \%$ of those patients leave before program completion [11]. Thus, in Iran, only $5 \%$ to $6 \%$ of patients complete outpatient CR programs. Given that the maximum effectiveness of $\mathrm{CR}$ programs depends on participation for 12 weeks or more [12], patients who drop out are more likely to experience future cardiac problems than are those who complete them [13]. Therefore, determination of the factors that make patients drop out of outpatient CR programs is necessary. To accomplish our goals, we observed patients who began outpatient CR and identified those who left the program before the end of the 11th week (session 22).

\section{MATERIALS AND METHODS}

\section{Design and procedure}

This was a retrospective study. Data were obtained from the CR center of Imam Ali Hospital in Kermanshah, Iran. Imam Ali Hospital is a government-run specialized cardiac center in western Iran that is generally visited by patients residing in western Iran. The database is comprised of information about patients who were registered in outpatient CR programs after an initial cardiac event. Initial cardiac events included coronary artery bypass graft surgery (CABG), percutaneous coronary intervention (PCI), myocardial infarction (MI), and valvular heart diseases (VHD). Outpatient CR was begun immediately after the patient was discharged from the hospital. Patients' walking practice at home was assessed via phone calls and a personal visit. Outpatient CR lasts for 12 weeks. It includes 24 sessions of monitored exercise (2 sessions a week) and a weekly joint session with a nutrition expert and a psychologist. Patients visit physicians for medication management. Patient demographics, type of cardiac problem and treatment method, comorbid conditions, health state indexes, treatment process, and session participation were recorded in the database. The registration forms were designed by heart and health specialists under the supervision of the Kermanshah University of Medical Sciences. The inspection unit of the university assessed the accuracy of the data several times a year. The present study examines the variables associated with those patients who did not complete the CR program. In order to evaluate the psychological state of the patients, such as whether they experienced anxiety or depression, standard tools like the Beck Scale were used at the beginning of the CR program. In the case of illiterate patients, the questionnaire was read to the patient by the clinical psychologist of the CR ward and the answers were immediately registered. Completion of the outpatient CR program was registered as follows: Leaving the course unfinished in each phase before the last week of outpatient CR: 1) Yes, 2) No, 3) Unspecified. It should be noted that this study is registered with the Research Center of Kermanshah University of Medical Sciences, Iran (93409) and has received ethical license from the Ethics Committee of the University. 


\section{Subjects}

The database includes information on 1,930 patients who were registered in the CR program between January 2001 and January 2013. One hundred forty individuals were immediately excluded from our study due to incomplete information, so we analyzed data from 1,790 patients. Certain items of information from some of the cases between 2001 and 2006 were missing, which caused SPSS ver. 21.0 for Windows (IBM SPSS, Armonk, NY, USA) to exclude 740 patients; thus, ultimately the sample size was 1,050 persons.

\section{Instruments}

\section{The Beck Anxiety Inventory (BAI)}

Beck et al. [14] designed a 21-item questionnaire to assess anxiety. Each item receives a score of 0-3, so the total score varies from 0 to 63 . A score of 0-7 indicates no anxiety; a score of 8-15 indicates mild anxiety; a score of 16-25 indicates moderate anxiety; and a score of 26-63 indicates severe anxiety. The internal consistency coefficient (Cronbach's alpha) of the exam is 0.92 , the consistency when retested within one week is 0.75 , and the consistency of the items varies from 0.30 to 0.76 . Five narrative types of content, concurrent, component, diagnostic and operative were assessed for this exam, all indicated the high efficiency of the tool to measure anxiety.

\section{The Beck Depression Inventory (BDI)}

In 1961, Beck and his colleagues designed a 21-item questionnaire to assess depression. Each item receives a score of 0-3; therefore, the total score varies from 0 to 63. A score of 0-4 indicates possible denial; 5-9 indicates very mild depression; 10-18 indicates mild to moderate depression; 19-29 indicates moderate to severe depression; and a score over 30 indicates severe depression. Beck et al. [15] reported the consistency when patients were retested within one week as 0.93 .

\section{Statistical analysis}

The characteristics of the patients who completed the CR program compared to those who dropped out were compared using a chi-square test for nominal and categorical variables and one-way variance analysis for consistent variables. Binary logistic regression analysis was used to identify the sociodemographic and psychological factors associated with quitting the CR program. Gender, age, education, marital status, occupational conditions, insurance coverage, distance to the CR center, treatment processes of CABG, PCI, MI, and VHD, exercise capacity, comorbid conditions (anxiety and depression), disease risk factors (diabetes, hypertension, obesity), and smoking history were all entered into analysis $(\mathrm{p}<0.05$ is considered statistically significant).

\section{RESULTS}

From a total of 1,050 patients (717 males and 333 females) registered in the CR program, 514 patients $(49 \%)$ completed the program and 536 (51\%) left it incomplete. The sociodemographic and psychological characteristics of the subjects as a whole and divided by completion vs. drop out are shown in Table 1. As shown, in the variables including gender, education, marital status, occupation, distance to CR, insurance coverage, exercise capacity, treatment procedures, depression, anxiety, blood pressure, diabetes, and smoking, there was a significant difference among the groups $(\mathrm{p}<0.01)$.

Table 2 displays the adjusted odds ratio, 95\% confidence interval, and p-value for each covariate included in the binary logistic regression model. The statistical assumptions needed for a valid binary logistic regression were met. The model was statistically significant overall $(\mathrm{p}<0.001)$. Of the 30 variables included as covariates in the regression, 13 were found to be independently significantly associated with completion of CR. Indicators of effect size showed suitable explanatory power with respect to completion of CR (Cox \& Snell $\mathrm{R}^{2}=0.431$; Nagelkerke $\mathrm{R}^{2}=0.575$ ). Elder illiterate patients, employees or retired individuals, individuals with low physical activity capacity, patients with high levels of depression and low levels of anxiety and non-current smokers were more likely to leave the program incomplete.

\section{DISCUSSION}

The present study was carried out to investigate the role of sociodemographic factors in failure to complete outpatient CR. In line with Moradi et al. [11] and Sarrafzadegan et al. [16], who reported that just $31.3 \%$ to $44.8 \%$ of cardiac patients in Iran who enroll in a CR program manage to complete it, the present study shows that fewer than half of the patients in the CR program (49\%) managed to 
Table 1. Baseline sociodemographic characteristics in the overall population and in those who completed and dropped out of CR

\begin{tabular}{|c|c|c|c|c|}
\hline & $\begin{array}{c}\text { Overall population } \\
(\mathrm{n}=\mathbf{1 , 0 5 0}, \mathbf{1 0 0 \%})\end{array}$ & $\begin{array}{c}\text { Completed CR } \\
(n=514,49 \%)\end{array}$ & $\begin{array}{l}\text { Dropped out of CR } \\
(n=536,51 \%)\end{array}$ & p-value ${ }^{a, b)}$ \\
\hline $\operatorname{Sex}(\%)$ & & & & $<0.001^{*}$ \\
\hline Male & 68.3 & 78.8 & 58.2 & \\
\hline Female & 31.7 & 21.2 & 41.8 & \\
\hline Age (yr) & $56.14 \pm 9.17$ & $55.79 \pm 8.86$ & $56.48 \pm 9.45$ & 0.23 \\
\hline Education degree (\%) & & & & $<0.001^{*}$ \\
\hline Illiterate & 41.0 & 30.1 & 51.5 & \\
\hline Less than diploma & 16.5 & 20.0 & 13.1 & \\
\hline Diploma & 16.4 & 18.9 & 14.0 & \\
\hline Academic & 13.1 & 16.0 & 10.4 & \\
\hline Other & 13.0 & 15.0 & 11.0 & \\
\hline Marital status (\%) & & & & $<0.001^{*}$ \\
\hline Single or divorced & 1.0 & 1.7 & 0.2 & \\
\hline Married & 86.3 & 82.2 & 90.5 & \\
\hline Other & 12.7 & 16.1 & 9.3 & \\
\hline Occupation & & & & $<0.001^{*}$ \\
\hline Market & 25.5 & 25.1 & 25.9 & \\
\hline Housewife & 29.1 & 17.9 & 39.7 & \\
\hline Retired & 23.4 & 30.7 & 16.5 & \\
\hline Clerk & 16.3 & 22.0 & 10.8 & \\
\hline Other & 5.7 & 4.3 & 7.1 & \\
\hline Distance to CR & & & & $<0.001^{*}$ \\
\hline No & 67.9 & 74.5 & 61.6 & \\
\hline Yes & 32.1 & 25.5 & 38.4 & \\
\hline Insurance & & & & $<0.001^{*}$ \\
\hline Yes & 99.5 & 99.2 & 99.8 & \\
\hline No & 0.5 & 0.8 & 0.2 & \\
\hline Exercise capacity & $7.59 \pm 4.03$ & $8.88 \pm 4.95$ & $6.35 \pm 2.27$ & $<0.001^{*}$ \\
\hline Index procedure (\%) & & & & $0.008^{*}$ \\
\hline CABG & 94.6 & 96.3 & 92.9 & \\
\hline Valvular & 1.5 & 0.5 & 2.4 & \\
\hline PCI & 1.4 & 0.8 & 1.1 & \\
\hline MI & 2.5 & 1.4 & 3.6 & \\
\hline \multicolumn{5}{|l|}{ Comorbidities } \\
\hline Depression & $15.53 \pm 5.97$ & $14.21 \pm 6.75$ & $16.79 \pm 4.79$ & $<0.001^{*}$ \\
\hline Anxiety & $21.85 \pm 19.21$ & $32.86 \pm 14.94$ & $11.30 \pm 16.80$ & $<0.001^{*}$ \\
\hline \multicolumn{5}{|l|}{ Cardiac risk factors (\%) } \\
\hline Diabetes & 7.1 & 6.0 & 9.5 & $0.003^{*}$ \\
\hline Hypertension & 12.5 & 10.1 & 14.7 & $0.005^{*}$ \\
\hline BMI & $26.50 \pm 4.07$ & $26.48 \pm 4.48$ & $26.51 \pm 3.86$ & 0.91 \\
\hline History of smoking (\%) & & & & $0.005^{*}$ \\
\hline Never & 59.0 & 57.8 & 60.3 & \\
\hline Cessation & 28.4 & 27.8 & 28.9 & \\
\hline Current smoker & 4.5 & 6.8 & 2.2 & \\
\hline Unknown & 8.1 & 7.6 & 8.6 & \\
\hline
\end{tabular}

Values are presented as mean \pm standard deviation or percentage (\%).

CABG, coronary artery bypass graft surgery; PCI, percutaneous coronary intervention; MI, myocardial infarction; BMI, body mass index; CR, cardiac rehabilitation.

${ }^{\text {a) }}$ Chi-square test performed for nominal and categorical variables.

${ }^{b)}$ ANOVA performed for continuous variables.

${ }^{*} \mathrm{p}<0.01$, significant difference between patients who completed and did not complete CR for each characteristic. 
Table 2. Predictors of completing CR in the overall population

\begin{tabular}{|c|c|c|c|}
\hline & Completed CR (\%) & Adjusted OR & p-value \\
\hline \multicolumn{4}{|c|}{ 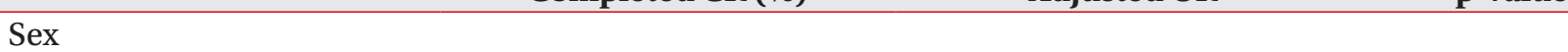 } \\
\hline Male & 56.5 & $1.44(0.52-3.97)$ & 0.48 \\
\hline Female & 32.7 & Referent & \\
\hline Age & - & $0.97(0.95-0.99)$ & $0.006^{* *}$ \\
\hline \multicolumn{4}{|l|}{ Education degree } \\
\hline Illiterate & 36.0 & $0.15(0.06-0.37)$ & $<0.001^{* *}$ \\
\hline Less than diploma & 59.5 & $0.13(0.05-0.34)$ & $<0.001^{* *}$ \\
\hline Diploma & 56.4 & $0.10(0.04-0.26)$ & $<0.001^{* *}$ \\
\hline Academic & 59.4 & $0.13(0.05-0.37)$ & $<0.001^{* *}$ \\
\hline Other & 56.6 & Referent & \\
\hline \multicolumn{4}{|l|}{ Marital status } \\
\hline Single or divorced & 90.0 & $0.12(0.01-1.65)$ & 0.11 \\
\hline Married & 46.5 & $0.81(0.39-1.69)$ & 0.58 \\
\hline Other & 62.4 & Referent & \\
\hline \multicolumn{4}{|l|}{ Occupation } \\
\hline Market & 48.1 & $0.59(0.26-1.35)$ & 0.21 \\
\hline Housewife & 30.2 & $1.31(0.38-4.44)$ & 0.67 \\
\hline Retired & 64.2 & $0.42(0.19-0.94)$ & $0.034^{*}$ \\
\hline Clerk & 66.1 & $0.36(0.15-0.84)$ & $0.017^{*}$ \\
\hline Other & 36.7 & Referent & \\
\hline \multicolumn{4}{|l|}{ Distance to CR } \\
\hline No & 53.7 & $1.36(0.89-2.07)$ & 0.15 \\
\hline Yes & 38.9 & Referent & \\
\hline \multicolumn{4}{|l|}{ Insurance } \\
\hline Yes & 45.0 & $1.56(0.75-3.24)$ & 0.24 \\
\hline No & 75.0 & Referent & \\
\hline Exercise capacity & - & $0.79(0.72-0.86)$ & $<0.001^{* *}$ \\
\hline \multicolumn{4}{|l|}{ Index procedure } \\
\hline CABG & 49.8 & $0.51(0.15-1.71)$ & 0.28 \\
\hline Valvular & 18.7 & $1.85(0.18-19.16)$ & 0.61 \\
\hline PCI & 60.0 & $0.75(0.13-4.39)$ & 0.75 \\
\hline MI & 26.9 & Referent & \\
\hline \multicolumn{4}{|l|}{ Comorbidities } \\
\hline Depression & - & $1.07(1.03-1.10)$ & $<0.001^{* *}$ \\
\hline Anxiety & - & $0.91(0.90-0.92)$ & $<0.001^{* *}$ \\
\hline \multicolumn{4}{|l|}{ Cardiac risk factors } \\
\hline Diabetes & 37.8 & $0.32(0.06-1.85)$ & 0.21 \\
\hline Hypertension & 39.7 & $0.90(0.16-5.10)$ & 0.90 \\
\hline Obesity & - & $0.98(0.94-1.03)$ & 0.53 \\
\hline \multicolumn{4}{|l|}{ History of smoking } \\
\hline Never & 47.9 & $0.08(0.04-0.16)$ & $<0.001^{* *}$ \\
\hline Cessation & 48.0 & $0.09(0.04-0.19)$ & $<0.001^{* *}$ \\
\hline Current smoker & 74.5 & $0.06(0.02-0.18)$ & $<0.001^{* *}$ \\
\hline Unknown & 45.9 & Referent & \\
\hline
\end{tabular}

The sociodemographic characteristics listed in this table were all included as covariates in the generation of the binary logistic regression model.

CABG, coronary artery bypass graft surgery; PCI, percutaneous coronary intervention; MI, myocardial infarction; BMI, body mass index; CR, cardiac rehabilitation; OR, odds ratio.

${ }^{*} \mathrm{p}<0.05,{ }^{* *} \mathrm{p}<0.01$, statistically significant odds ratio for each characteristic. 
complete it. This is vital information given that numerous studies $[1,3,17]$ have noted the importance of a CR program and have shown that the maximum advantages of CR programs is obtained by participation for 12 weeks or more [12]. Patients who drop out of CR programs are more likely to experience future cardiac complications than are those who complete them [13]. Blanchard et al. [18] reported only a $4 \%$ dropout rate, which is a large departure from Iranian dropout statistics. While this is more pertinent to the Iranian way of hospital planning and administrative system, one must not overlook factors such as the narrowed knowledge of Iranian physicians and patients about the benefits of CR program [11].

The results of this study unveiled that factors such as illiteracy, aging, being an employee or retired, low exercise capacity, high levels of depression, low levels of anxiety, and non-current smoking status were significantly associated with failure to complete CR. Sanderson et al. [19] suggested that non-medical issues explained for a $63 \%$ dropout rate in their study; such non-medical issues included education, age and occupation. As was mentioned by Moradi et al. [11], the illiteracy rate could affect the dropout rate because of factors such as difficulty in understanding trainings and inability to study educational brochures and understand behavioral requirements. Also, illiterate individuals may feel insecure asking for help understanding materials, so they may choose to drop out of the program. These patients, who are mostly elderly, are less knowledgeable in general about the advantages of CR [20]. Illiteracy and low educational levels are higher among elderly patients in their retirement period. Notably, a previous study [21] showed that patients 70 years of age or older were less likely to participate in and finish a CR course than were younger patients. Growing older, patients experience a decline in general physical ability, which directly affects the decrease in the number of patients completing a CR course [22]. Also, growing old indirectly impacts most barriers to CR [20], which could explain the effect of age on the decreasing number of patients.

In agreement with results from several previous studies $[19,22,23]$, we showed that the dropout rate was higher among employees, as they have a limited amount of time off work and the timing of CR sessions may interfere with their work. It is reasonable to think that management of personal and work affairs would get in the way of CR pro- gram completion amongst employed individuals [24].

Another finding of our study was that patients with limited capacity for exercise were more likely to leave the program. Patients with lower exercise capacity were often older and declared that they found themselves less active in comparison to others; they also reported finding physical activities boring and/or painful [20]. Similarly, Worcester et al. [21] showed that elderly patients and women with limited physical capabilities were more likely to leave the program earlier.

In line with a study by Yohannes et al. [25], our results showed that higher levels of depression were associated with failure to complete the program. Van der Wal et al. [26] point out that acceptance of medical recommendations is hindered by depression. In patients with depressive disorders, a lack of in interest and enjoyment in life is generally present and nearly all daily activities are affected; the individual is confronted by psycho-kinetic dullness, fatigue, and energy loss. Thus, it makes sense that cardiac patients with higher levels of depression would be reluctant to join long-term, active CR programs [27]. Depressed people take less care of themselves and exhibit lower levels of physical activity. Depression leads to poor medical and dietary follow-up and less behavioral modification and improvement in cardiac risk factors, and depressed patients are more likely to quit their exercise programs [28].

We also found that patients with lower levels of anxiety were more likely to quit CR programs. Anxiety is the first and most common reaction to a cardiac event [3]. High levels of health-related anxiety may persuade patients to complete CR programs in an attempt to prevent future cardiac events. Low anxiety levels may indicate that patients have less comprehension of disease consequences. According to Yohannes et al. [25], individuals with weaker understanding of disease consequences and faith in the treatment process on the one hand, and higher perception of personal control on the other hand, were more likely to leave a CR program. In this regard, Michie et al. [29] suggested that lower levels of anxiety resulted from a feeling of dominance and more personal control over cardiac conditions, which could explain why such individuals drop out of CR programs.

Our study showed that current smokers were less likely to leave CR programs unfinished, which agrees with a report by Turk-Adawi et al. [30]. Fischer et al. [31] suggested 
that creating a positive outlook on treatment and creating trust in the treatment process among patients significantly improves the dropout rate. Patients who smoke often hope to decrease how much they smoke or quite entirely by the end of the program. Such positive expectations, which are strengthened by the CR team, may be a protective factor.

Finally, in contrast with previous studies [23,32], we found that the distance to the CR facility and having health service insurance did not affect the dropout rate. This may be explained by one important difference in the methods of the researchers in our study: after the first phase of treatment and before the patients left the hospital, the patients were invited to take part in a briefing session and asked to attend the next phase of the CR program. In the briefing session, researchers discussed the advantages of the CR program, start time of the program, number of sessions, duration of each session, expenses and health insurance, and the importance of regular participation in the program. This was done in order to let each patient consciously decide whether or not to enroll in the program. Therefore, before the second phase of $\mathrm{CR}$, a large number of patients left the program because of financial problems or difficulty traveling to the center, and only those for whom health insurance and distance were not problematic remained in the study. Most patients lacking health insurance did not enroll in the program. On the other hand, most of the patients lived in cities close to the CR center and were able to commute to the center in under 90 minutes. So, distance to the center was not a problem for most patients.

Incomplete cases and missing data which led to the exclusion of nearly one-third of the patients from analysis was among the limitations of this study. Since the management of this center has changed several times in recent years, it is possible that the reason for the existence of incomplete cases and missing data was mismanagement.

In conclusion, consistent with a few studies done in Iran, the results of the present study showed that the dropout rate of patients in a CR program was $51 \%$. This is much higher than the rate reported in other countries (4\%). Paying more attention to older patients with low literacy levels and limited exercise capacity, who are employed or retired, and who are not current smokers, and taking therapeutic measures to control psychologi- cal complications such as depression, may be effective in ensuring that patients complete outpatient cardiac rehabilitation.

\section{CONFLICT OF INTEREST}

No potential conflict of interest relevant to this article was reported.

\section{ACKNOWLEDGMENTS}

It is hereby deemed necessary to thank and appreciate the Chancellor and Research Vice Chancellor of Kermanshah University of Medical Sciences and the staff of the CR ward of the Imam Ali Hospital for their cooperation in providing data.

\section{REFERENCES}

1. Karami J, Komasi S, Maesoomi M, Saeidi M. Comparing the effects of two methods of relaxation and interpersonal cognitive problem solving (ICPS) on decreasing anxiety and depression in cardiac rehabilitation patients. Urmia Med J 2014;25:298-308.

2. Hajali Akbari Z, Hosseini MA, Nourozi K, Rahgozar M. Comparing barriers and facilitators of attending to cardiac rehabilitation programs from patients with coronary artery bypass graft surgery and rehabilitation specialists' viewpoints. Iran J Rehabil Res Nurs 2014;1:62-73.

3. Bath J, Bohin G, Jones C, Scarle E. Cardiac rehabilitation: a workbook for use with group programmes. Chichester: John Wiley \& Sons; 2009.

4. World Health Organization. Needs and action priorities in cardiac rehabilitation and secondary prevention in patients with coronary heart disease. Geneva: World Health Organization; 1993.

5. Proudfoot C. Cardiac rehabilitation. In: Thow MK, editor. Exercise leadership in cardiac rehabilitation: an evidence-based approach. Chichester: John Wiley \& Sons; 2006. p. 9-13.

6. Williams MA, Ades PA, Hamm LF, Keteyian SJ, LaFontaine TP, Roitman JL, et al. Clinical evidence for a health benefit from cardiac rehabilitation: an update. Am Heart J 2006;152:835-41.

7. Jackson L, Leclerc J, Erskine Y, Linden W. Getting the 
most out of cardiac rehabilitation: a review of referral and adherence predictors. Heart 2005;91:10-4.

8. Witt BJ, Thomas RJ, Roger VL. Cardiac rehabilitation after myocardial infarction: a review to understand barriers to participation and potential solutions. Eura Medicophys 2005;41:27-34.

9. Dohnke B, Nowossadeck E, Muller-Fahrnow W. Motivation and participation in a phase III cardiac rehabilitation programme: an application of the health action process approach. Res Sports Med 2010;18:21935.

10. Moradi B, Maleki M, Esmaeilzadeh M, Bakhshandeh Abkenar H. Physician-related factors affecting cardiac rehabilitation referral. J Tehran Heart Cent 2011;6:18792.

11. Moradi B, Esmaeilzadeh M, Maleki M, Sari L. Factors associated with failure to complete phase II cardiac rehabilitation: survey registry in Rajaie cardiovascular medical and research center. Int Cardiovasc Res J 2011;5:139-42.

12. Oldridge NB, Guyatt GH, Fischer ME, Rimm AA. Cardiac rehabilitation after myocardial infarction. Combined experience of randomized clinical trials. JAMA 1988;260:945-50.

13. Taylor GH, Wilson SL, Sharp J. Medical, psychological, and sociodemographic factors associated with adherence to cardiac rehabilitation programs: a systematic review. J Cardiovasc Nurs 2011;26:202-9.

14. Beck AT, Epstein N, Brown G, Steer RA. An inventory for measuring clinical anxiety: psychometric properties. J Consult Clin Psychol 1988;56:893-7.

15. Beck AT, Steer RA, Garbin MG. Psychometric properties of the Beck Depression Inventory: twenty-five years of evaluation. Clin Psychol Rev 1988;8:77-100.

16. Sarrafzadegan N, Rabiei K, Shirani S, Kabir A, Mohammadifard N, Roohafza $\mathrm{H}$. Drop-out predictors in cardiac rehabilitation programmes and the impact of sex differences among coronary heart disease patients in an Iranian sample: a cohort study. Clin Rehabil 2007;21:362-72.

17. Lavie CJ, Milani RV, Lavie TJ. Impact of cardiac rehabilitation, exercise training, and fitness on psychological distress. In: Sher L, editor. Psychological factors and cardiovascular disorders: the role of stress and psychological influences. New York: Nova Science Publishers Inc.; 2009. p. 314-20.
18. Blanchard CM, Courneya KS, Rodgers WM, Fraser SN, Murray TC, Daub B, et al. Is the theory of planned behavior a useful framework for understanding exercise adherence during phase II cardiac rehabilitation? J Cardiopulm Rehabil 2003;23:29-39.

19. Sanderson BK, Phillips MM, Gerald L, DiLillo V, Bittner V. Factors associated with the failure of patients to complete cardiac rehabilitation for medical and nonmedical reasons. J Cardiopulm Rehabil 2003;23:281-9.

20. Grace SL, Shanmugasegaram S, Gravely-Witte S, Brual J, Suskin N, Stewart DE. Barriers to cardiac rehabilitation: DOES AGE MAKE A DIFFERENCE? J Cardiopulm Rehabil Prev 2009;29:183-7.

21. Worcester MU, Murphy BM, Mee VK, Roberts SB, Goble AJ. Cardiac rehabilitation programmes: predictors of non-attendance and drop-out. Eur J Cardiovasc Prev Rehabil 2004;11:328-35.

22. Mikkelsen T, Korsgaard Thomsen K, Tchijevitch O. Non-attendance and drop-out in cardiac rehabilitation among patients with ischaemic heart disease. Dan Med J 2014;61:A4919.

23. Grace SL, Gravely-Witte S, Brual J, Monette G, Suskin $\mathrm{N}$, Higginson L, et al. Contribution of patient and physician factors to cardiac rehabilitation enrollment: a prospective multilevel study. Eur J Cardiovasc Prev Rehabil 2008;15:548-56.

24. De Vos C, Li X, Van Vlaenderen I, Saka O, Dendale P, Eyssen $\mathrm{M}$, et al. Participating or not in a cardiac rehabilitation programme: factors influencing a patient's decision. Eur J Prev Cardiol 2013;20:341-8.

25. Yohannes AM, Yalfani A, Doherty P, Bundy C. Predictors of drop-out from an outpatient cardiac rehabilitation programme. Clin Rehabil 2007;21:222-9.

26. van der Wal MH, Jaarsma T, Moser DK, Veeger NJ, van Gilst WH, van Veldhuisen DJ. Compliance in heart failure patients: the importance of knowledge and beliefs. Eur Heart J 2006;27:434-40.

27. American Psychiatric Association. Diagnostic and statistical manual of mental disorders (DSM-5). 5nd ed. Washington: American Psychiatric Association; 2013. p. 233-50.

28. Vaccarino V, Bremner JD. Psychiatric and behavioral aspects of cardiovascular disease. In: Bonow RO, Mann DL, Zipes DP, Libby P, editors. Braunwald's Heart disease: a text book of cardiovascular medicine. 9th ed. Philadelphia: Saunders; 2012. p. 1904-15. 
29. Michie S, O'Connor D, Bath J, Giles M, Earll 1. Cardiac rehabilitation: The psychological changes that predict health outcome and healthy behaviour. Psychol Health Med 2005;10:88-95.

30. Turk-Adawi KI, Oldridge NB, Tarima SS, Stason WB, Shepard DS. Cardiac rehabilitation enrollment among referred patients: patient and organizational factors. J Cardiopulm Rehabil Prev 2014;34:114-22.

31. Fischer MJ, Scharloo M, Abbink JJ, van 't Hul AJ, van
Ranst D, Rudolphus A, et al. Drop-out and attendance in pulmonary rehabilitation: the role of clinical and psychosocial variables. Respir Med 2009;103:1564-71.

32. Grace SL, Gravely-Witte S, Brual J, Suskin N, Higginson L, Alter D, et al. Contribution of patient and physician factors to cardiac rehabilitation referral: a prospective multilevel study. Nat Clin Pract Cardiovasc Med 2008;5:653-62. 